\title{
Copy number variation of human AMY1 is a minor contributor to variation in salivary amylase expression and activity
}

\author{
Danielle Carpenter, Laura M. Mitchell and John A. L. Armour
}

\begin{abstract}
Background: Salivary amylase in humans is encoded by the copy variable gene AMY1 in the amylase gene cluster on chromosome 1. Although the role of salivary amylase is well established, the consequences of the copy number variation (CNV) at AMY1 on salivary amylase protein production are less well understood. The amylase gene cluster is highly structured with a fundamental difference between odd and even AMY1 copy number haplotypes. In this study, we aimed to explore, in samples from 119 unrelated individuals, not only the effects of AMY1 CNV on salivary amylase protein expression and amylase enzyme activity but also whether there is any evidence for underlying difference between the common haplotypes containing odd numbers of AMY1 and even copy number haplotypes.

Results: AMY1 copy number was significantly correlated with the variation observed in salivary amylase production (11.7\% of variance, $P<0.0005)$ and enzyme activity $(13.6 \%$ of variance, $P<0.0005)$ but did not explain the majority of observed variation between individuals. AMY1-odd and AMY1-even haplotypes showed a different relationship between copy number and expression levels, but the difference was not statistically significant $(P=0.052)$.
\end{abstract}

Conclusions: Production of salivary amylase is correlated with AMY1 CNV, but the majority of interindividual variation comes from other sources. Long-range haplotype structure may affect expression, but this was not significant in our data.

Keywords: Genome instability, Amylase, CNV, Gene expression

\section{Introduction}

The enzyme amylase plays a major role in starch hydrolysis, which begins in the oral cavity and continues into the stomach and then small intestine. Amylase is the most abundant protein in saliva, accounting for at least $50 \%$ of salivary protein [1], but the quantity and enzyme activity of salivary amylase varies greatly among individuals. This variation in amylase production could be attributable to a number of factors including environmental factors, such as stress [2] and circadian rhythms [3], oral health [4] and the genetic background of an individual's amylase gene cluster. Whilst it has been suggested that quantitative variation in amylase protein patterns does not always reflect variation in the amylase gene cluster [5], some studies have shown a relationship between the observed copy number variation $(\mathrm{CNV})$ at the salivary amylase gene

\footnotetext{
* Correspondence: john.armour@nottingham.ac.uk

School of Life Sciences, University of Nottingham, Nottingham NG7 2UH, UK
}

$(A M Y 1)$ and an increased level of amylase protein expression [6, 7]. Perry et al. [7], using immunoblotting to investigate amylase protein levels, identified a significant positive correlation $(R=0.59)$ between $C N V$ at $A M Y 1$ and levels of amylase protein in saliva. Mandel and colleagues [6], also using immunoblotting, observed a similar correlation $(R=0.50)$ with copy number at $A M Y 1$ and amylase protein levels as well as a correlation $(R=0.52)$ between $\mathrm{CNV}$ at $A M Y 1$ and salivary enzyme activity. These results suggest that approximately $20-35 \%$ of the variance in salivary amylase expression can be attributed to variation in $A M Y 1$ copy number.

The human amylase genes form a cluster on chromosome 1 which contains both the salivary (AMY1) and pancreatic $(A M Y 2)$ amylase genes, both of which vary in copy number $[5,8,9]$. The CNV at $A M Y 1$ has an observed range of 2-18 copies per person [7, 10-12] and an average of 6 copies per person, whilst the CNV at $A M Y 2$ has an observed range of 2-12 copies per person and an average 
of 4 copies per person. The amylase gene cluster is highly structured [13-15], with a correlation between the CNV at $A M Y 1$ and the CNV at $A M Y 2[10,12]$. Recent observations have identified a fundamental difference in the underlying genomic structure across the amylase gene cluster between majority haplotypes containing an odd number of copies of $A M Y 1$ and one copy each of $A M Y 2 A$ and $A M Y 2 B$, and less common variant haplotypes containing even copy number haplotypes of $A M Y 1$ and deletions or duplications of $A M Y 2$ genes. Consequently, the majority of individuals (60-70\%), with two $A M Y 1$-odd haplotypes, have an even copy number of $A M Y 1$ and no CNV of $A M Y 2$, whereas those individuals with an odd copy number of $A M Y 1$ (usually heterozygous for an $A M Y 1$-even haplotype) also display CNV of $A M Y 2$ [10, 12].

Previous studies investigating the relationship between $\mathrm{CNV}$ at $A M Y 1$ and salivary amylase protein expression have used qPCR to measure copy number. However, qPCR measurement of $A M Y 1$ has since been shown to be subject to systematic error and, in one study, consistently underestimated the $A M Y 1$ copy number $[7,10]$. We aimed to re-evaluate the relationship between $\mathrm{CNV}$ at $A M Y 1$ and salivary amylase protein expression using alternative copy number measurement methods that have been shown to be precise and reproducible [10]. Our experimental plan was designed to measure both the expression of salivary amylase total protein and amylase enzyme activity in saliva from a larger cohort of individuals than has been previously studied, in parallel with determination of copy number at $A M Y 1$. Knowledge of the haplotype structures also allows us to test whether all copies of $A M Y 1$ are functionally equivalent or whether there is any evidence for context dependence of gene expression. Therefore, our aim is to explore the functional consequences of the multi-allelic copy variable gene $A M Y 1$ on more $(N=119)$ samples than previously investigated and using novel methods of $A M Y 1$ copy number measurement, capable of resolving single integer copy numbers.

\section{Results}

\section{Variation in AMY1 and AMY2 copy numbers}

Copy number measurement of both $A M Y 1$ and $A M Y 2$ was performed on all 119 independent UK samples (see "Methods"). The AMY1 copy number distribution is shown in Fig. 1 and shows a predominance of even copy numbers $(75 \%)$, with a range of $2-15$ and a modal copy number of 6 , consistent with prior studies of $A M Y 1$ copy number [7, 10-12]. Variation in $A M Y 2$ copy number was also observed with $A M Y 2 A$ copy variable in $24 \%$ of samples and $A M Y 2 B$ showing $C N V$ in about $10 \%$ of samples (Table 1).

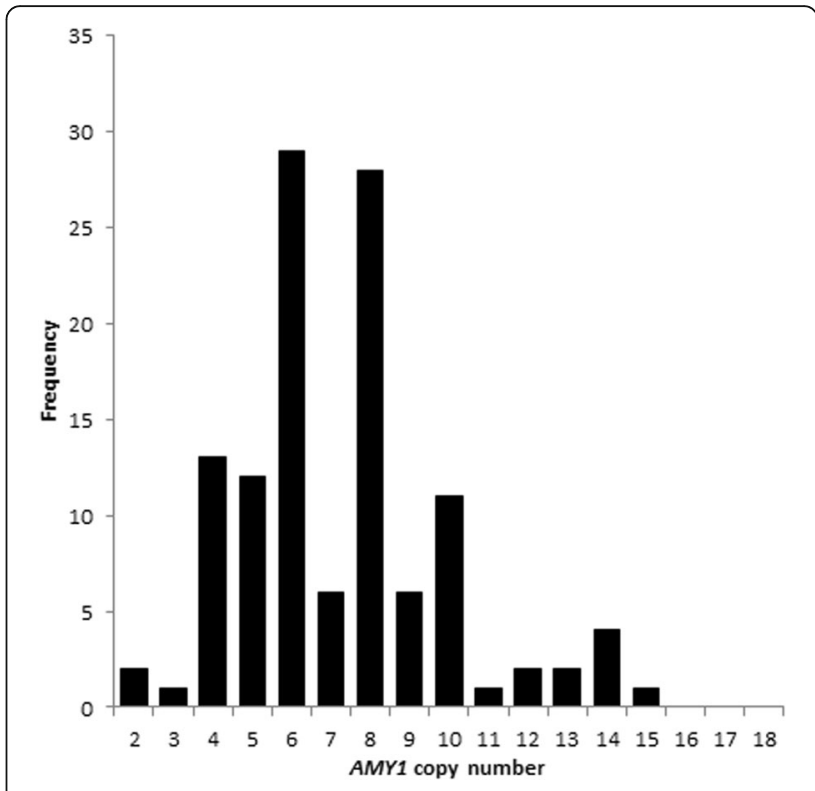

Fig. 1 Distribution histogram of AMY1 copy number in 119 unrelated UK samples; a clear majority have even copy numbers (89 out of 119)

\section{Correlation of AMY1 copy number with protein production and enzyme activity}

We investigated both amylase protein levels and salivary amylase enzyme activity. Our data are consistent with previous studies in exhibiting considerable variation in protein expression $[6,7]$ and include some samples (across all copy numbers) with very low amounts of amylase protein (lowest value $0.48 \mathrm{mg} / \mathrm{mL}$ ), as also detected by Mandel et al. [6].

The raw data for total protein (antigen) concentration (Fig. 2) and for enzyme activity (Fig. 3) did not show a strong relationship with copy number, and the residuals of the regression are far from normally distributed (Additional file 1: Figure S2). A linear regression was performed using $\log _{10}$ of protein and of enzyme activity giving residuals that follow a normal distribution (Additional file 1: Figure S2) and satisfy other assumptions of linear regression modelling, and therefore, all further analyses were performed with the transformed data.

Table 1 CNV of AMY2 in 119 UK samples studied

\begin{tabular}{lll}
\hline Copy number & AMY2A & AMY2B \\
\hline 0 & 0 & 0 \\
1 & 14 & 0 \\
2 & 91 & 107 \\
3 & 13 & 12 \\
4 & 1 & 0 \\
TOTAL & 119 & 119 \\
\hline
\end{tabular}




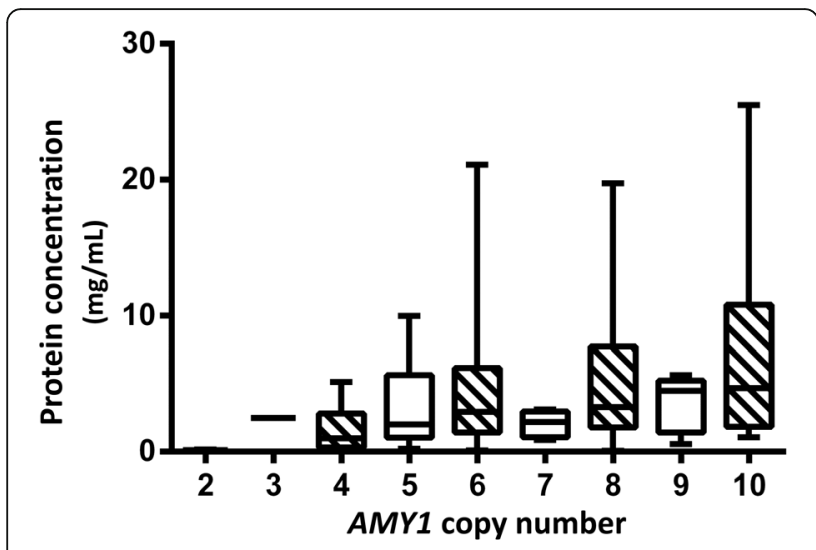

Fig. 2 A box and whiskers plot of amylase protein concentration by AMY1 copy number, with mean for all samples at a given copy number shown as a black bar, the standard deviation as the box, and whiskers showing the observed full range of data. Each contributing data point is the mean of three experimental replicates, and further details of biological replicates from the same subjects can be found in the "Methods"

A significant correlation was observed between $A M Y 1$ copy number and amylase protein $(R=0.342)(P<0.0005)$. Our data suggests that $A M Y 1$ copy number accounts for $11.7 \%$ of the variation observed in salivary amylase protein levels, much less than previous reports of 35\% from a study of 50 European American individuals [7], and 25\% in a study of 62 individuals of unspecified ancestry [6]. Our observation suggests that the $\mathrm{CNV}$ at $A M Y 1$ plays much less of a role in the variation of salivary amylase protein levels than previously proposed. Furthermore, the great spread of observed levels of amylase protein

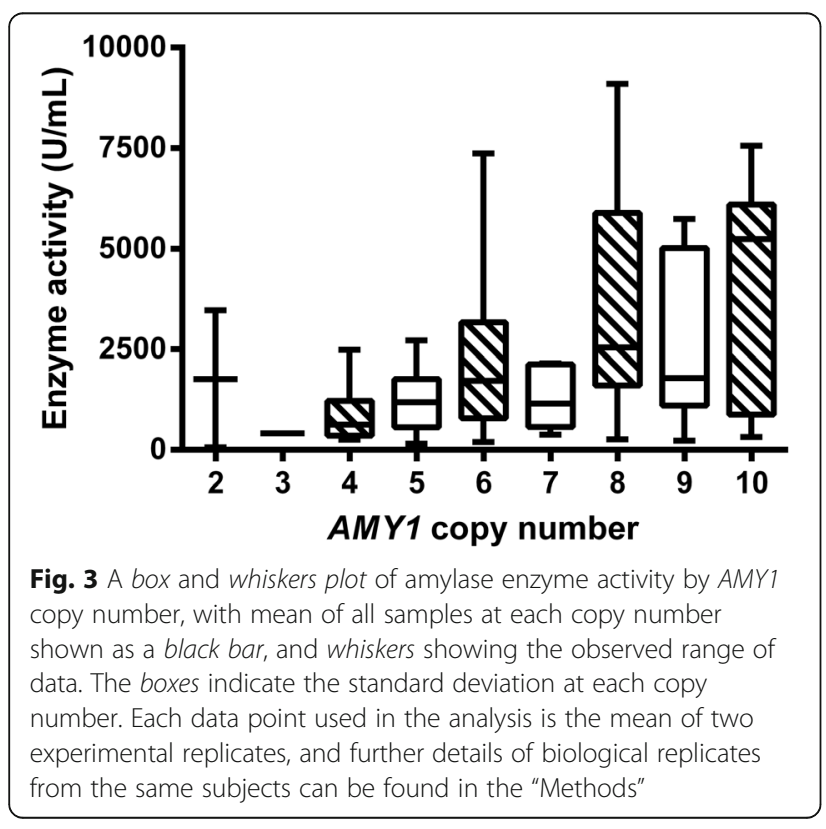

production suggests that the genetic contribution of the $\mathrm{CNV}$ is not simply proportional to protein production.

A similar relationship was observed with salivary amylase enzyme activity. A significant correlation was observed between $A M Y 1$ copy number and enzyme activity $(R=0.369)$ $(P<0.0005)$. Again, our data suggest that copy number plays less of a role than previously reported, with copy number accounting for $13.6 \%$ of the variation in enzyme activity observed in our study, rather than $27 \%$ as previously suggested [6]. A similar observation was reported in a Chinese population $(n=92)$ which found the gene copy number provided $12.2 \%$ of the observed salivary enzyme activity variation [16]. However, direct comparison between these studies is not straightforward, as Chinese populations do have a distinct $A M Y 1$ distribution to Europeans [10, 12].

As our copy number measurement system is accurate enough to assign single integers, we were able to investigate whether there are differences in gene expression between those individuals that have even $A M Y 1$ copy numbers and those with odd. We fitted a logistic regression model to protein and copy number data and used the model to predict protein expression from copy number to examine whether the odd or even number status was associated with a systematic difference in the relationship. This analysis gave marginally non-significant evidence $(P=0.052)$ for a difference between the regressions of log protein with even $(R=0.168)$ and odd $(R=0.017)$ copy numbers (Additional file 1: Figure S3), suggesting that the relationship between copy number and protein may be different for the odd and even copy numbers.

\section{Discussion}

This is only the second study to investigate both protein levels and enzyme activity in the same samples. There is a highly significant correlation between the two measures $(R=0.66 ; P<0.0001)$ (Additional file 1: Figure $S 4)$; whilst this is not a strong relationship, it is consistent with previous observations between these two measures ( $R=0.61)$ [6]. This observation does suggest that for a particular quantity of amylase protein, there are variations in measurable enzyme activity, and supports the proposal that the enzymatic functions of amylase may be affected by protein modifications or the formation of complexes [6, 17].

With the complex underlying structure at the amylase gene cluster, it is possible that longer-range structure, including the $\mathrm{CNV}$ at $A M Y 2$, may influence $A M Y 1$ expression, but there was no significant correlation observed between $C N V$ at either $A M Y 2 A$ or $A M Y 2 B$ with either salivary amylase protein production or enzyme activity.

\section{Conclusions}

To re-assess the relationship between copy number and salivary amylase protein expression and activity, our 
work used a more accurate and precise $A M Y 1$ copy number measurement method than the qPCR methods previously employed. Our previous work demonstrated the reliability of PRT-based methods and the susceptibility of qPCR methods to measurement error [10]. Our data clearly show that copy number plays much less of a role in salivary amylase expression and activity than has been previously suggested, and that it is not possible to predict an individual's salivary amylase concentration or enzyme activity solely from their copy number, with implications for studies of the effects of $A M Y 1$ copy number variation, such as with diet. It is interesting to speculate on possible reasons for the differences between our results and those of other researchers. In addition to the improved methodology for copy number measurement, there may also have been differences in the sampling regime for saliva; in our work, we specified the method and time of collection but did not examine or standardise other factors, such as the timing relative to meals. Because of the fundamental structural difference between haplotypes containing odd or even numbers of copies, we wanted to test the possibility that odd or even number haplotypes might have different relationships between copy number and gene expression. Our data neither confirm nor exclude functional differences that arise from the underlying genomic structure across the amylase region between odd and even copy number haplotypes. Further studies would be needed to support the idea, but it does remain possible that the longerrange genomic structure, in addition to $A M Y 1$ copy number itself, may have a role in determining variation in gene expression.

\section{Methods}

\section{Study population}

Our analysis utilised 120 independent volunteers from the University of Nottingham staff and student body, with 10 randomly selected to provide repeat samples. The blood, for DNA extraction, and saliva, for salivary amylase analysis, were taken with full consent from individuals and under local ethical approval (University of Nottingham Medical School Ethics Committee approval reference number BT10/02/2010). All samples were of the UK origin with no known clinical phenotype. DNA was extracted using isolated lymphocytes and a standard 'salting out' method for protein removal followed by phenol-chloroform extraction. DNA concentration was measured using a NanoDrop spectrophotometer, and DNA purity was assessed from the 260:280 nm absorbance ratio. All samples were diluted to a working concentration of $10 \mathrm{ng} / \mathrm{mL}$. DNA was successfully extracted for all samples, except one, giving a total sample size of 119 independent individuals.

\section{Sample preparation}

The saliva samples were collected from each volunteer at approximately $9.30 \mathrm{am}(+/-10 \mathrm{~min})$. The volunteers chewed on a $4 \mathrm{~cm}$ piece of parafilm for $30 \mathrm{~s}$ to allow saliva to be produced and then collected into a $15 \mathrm{ml}$ sterile polypropylene container. The tubes were centrifuged at $13 \mathrm{rpm}$ for $5 \mathrm{~min}$ to remove any solids from the suspension, and the remaining saliva was stored at $-80^{\circ}$ C. For genotyping, $20 \mathrm{~mL}$ of the whole blood was taken from each volunteer from which genomic DNA was isolated and stored at $-80{ }^{\circ} \mathrm{C}$.

\section{Measurement of AMY1 and AMY2 copy numbers}

The copy number of $A M Y 1$ was measured from genomic DNA using a paralogue ratio test (PRT) in combination with a TATC microsatellite assay, as previously described [10]. $A M Y 2$ copy number was measured using an $A M Y 2 A: A M Y 2 B$ ratio assay, an $A M Y 2 A: A M Y 2 A$ pseudogene ratio assay and an $A M Y 2 A / 2 B$ duplication junction assay, as previously described [10].

PRT PCR reactions were performed using previously described primers PRT_ref12 [10] that amplify from each copy of $A M Y 1$ and from a reference locus at hg19 chr12:9,867,565-9,867,813. PCR products were mixed with $10 \mu \mathrm{l} \mathrm{HiDi}$ formamide with ROX-500 marker (Applied Biosystems, Warrington, UK), and subsequent fragment analysis was carried out by electrophoresis on an ABI3130xl $36 \mathrm{~cm}$ capillary using POP-7 polymer with an injection time of $30 \mathrm{~s}$ at $1 \mathrm{kV}$. GeneMapper software (Applied Biosystems, Warrington, UK) was used to extract the peak areas for the PRT and calculate the ratio of test (244 bp) to reference (249 bp) products. Copy number values were calculated by calibrating the ratios using HapMap CEU samples [NA11930 with $A M Y 1$ copy number $(\mathrm{CN})=2$; NA06993 with $\mathrm{CN}=6$; NA10852 with $\mathrm{CN}=6$; NA10835 with $\mathrm{CN}=$ 8; NA12248 with $\mathrm{CN}=8$; NA11931 with $\mathrm{CN}=8$; NA11993 with $\mathrm{CN}=10$ and NA07347 with $\mathrm{CN}=11$ ], which were included in every experiment in duplicate.

For further confirmation of $A M Y 1$ gene copy number, a TATC microsatellite PCR was performed for each sample [10]. A single PCR reaction was performed and the products were mixed with $10 \mu \mathrm{l} \mathrm{HiDi}$ formamide with ROX-500 marker (Applied Biosystems, Warrington, UK), and fragment analysis was carried out by electrophoresis on an ABI3130xl $36 \mathrm{~cm}$ capillary using POP-7 polymer with an injection time of $30 \mathrm{~s}$ at $1 \mathrm{kV}$. GeneMapper software (Applied Biosystems, Warrington, UK) was used to extract the peak areas.

The ratio of $A M Y 2 A$ copy number to $A M Y 2 B$ copy number and the ratio of $A M Y 2 A$ copy number to $A M Y 2 A$ pseudogene copy number were measured as previously described [10]. One microliter of PCR products from both assays were mixed and added to $10 \mu \mathrm{l}$ 
HiDi formamide with ROX-500 marker (Applied Biosystems, Warrington, UK), and fragment analysis was carried out by electrophoresis on an ABI3130xl $36 \mathrm{~cm}$ capillary using POP-7 polymer, injecting at $1 \mathrm{kV}$ for $10 \mathrm{~s}$. GeneMapper software (Applied Biosystems, Warrington, UK) was used to extract the peak areas and calculate the ratio of $A M Y 2 A$ (163 bp) to $A M Y 2 B(167 \mathrm{bp})$ and the ratio of $A M Y 2 A$ (197 bp) to $A M Y 2 A$ pseudogene (232 bp).

The $A M Y 2 A / 2 B$ duplication junction assay is a threeprimer assay producing PCR amplicons of $424 \mathrm{bp}$ in all samples and a specific 323 bp only from the duplication junction. The products were visualised on a $2 \%(w / v)$ agarose gel, as previously described [10].

\section{Measurement of amylase protein}

The concentration of amylase protein antigen present in the saliva was measured using a sandwich amylase ELISA with $1 \mu \mathrm{g} / \mathrm{mL}$ of anti-salivary amylase antibody (Abcam, Cambridge, UK) and $100 \mu \mathrm{g} / \mathrm{mL}$ of biotinylated detection antibody (Biorbyt, Cambridge, UK). Assays were performed using serial dilutions (1:5) of natural human salivary amylase protein of known concentration $(200 \mu \mathrm{g} / \mathrm{mL})$ (Sigma-Aldrich, Gillingham, Dorset, UK) to generate a standard curve. Assays were performed in duplicate for each unknown sample, and the standard curve was measured in triplicate.

\section{Measurement of amylase enzyme activity}

The amylase enzyme activity within saliva was measured using the EnzCheck ${ }^{\circ}$ Ultra Amylase Assay Kit (Invitrogen, ThermoFisher, Paisley, UK) according to manufacturer's instructions. The saliva samples were added to the substrate solution, vortexed, and the fluorescence of the samples was measured after $10 \mathrm{~min}$ incubation at room temperature. Assays were performed using serial dilutions (1:5) of natural salivary amylase protein of known concentration $(200 \mu \mathrm{g} / \mathrm{mL})$ (Sigma-Aldrich, Gillingham, Dorset, UK) to generate a standard curve. Assays were performed in duplicate for each unknown sample, and the standard curve was measured in triplicate.

In order to deduce the variation in concentration for protein expression and enzyme activity within each individual, the repeat samples from an initial cohort of 10 individuals were investigated on four separate occasions (Additional file 1: Figure S1). These 10 repeat samples comprise samples with $2(\times 1), 4(\times 1), 6(\times 4), 8(\times 2)$ and 9 ( $\times 2)$ copies of $A M Y 1$. Analysis of repeat measures found that neither of the within-subject factors (time and measurement) was significant for measurement of salivary amylase protein expression or enzyme activity, and therefore, a single time point is suitable for comparing measurements of salivary amylase protein and enzyme activity between individuals.

\section{Bradford assay for measurement of total protein concentration}

The total protein concentration in the saliva samples was measured using Bradford Reagent (Sigma-Aldrich, Gillingham, Dorset, UK) according to manufacturer's instructions. Assays were performed using serial dilutions (1:2) of bovine serum albumin (BSA) protein of known concentration $(1.4 \mathrm{mg} / \mathrm{mL})$ (Sigma-Aldrich, Gillingham, Dorset, UK) to generate a standard curve. Assays were performed in duplicate for each unknown sample, and the standard curve measured in triplicate.

\section{Statistical analysis}

Correlations between groups of copy number data and either protein expression or enzyme activity were assessed using logistic regression in SPSS V22 (IBM, Armonk, New York, USA), and figures were drawn with the software GraphPad Prism (GraphPad Software, Inc., La Jolla, CA, USA). The repeat measures were analysed in SPSS using a general linear model with repeated measures, with the within-subject factors defined as time and measurement and the between-subject factor defined as copy number.

\section{Additional files}

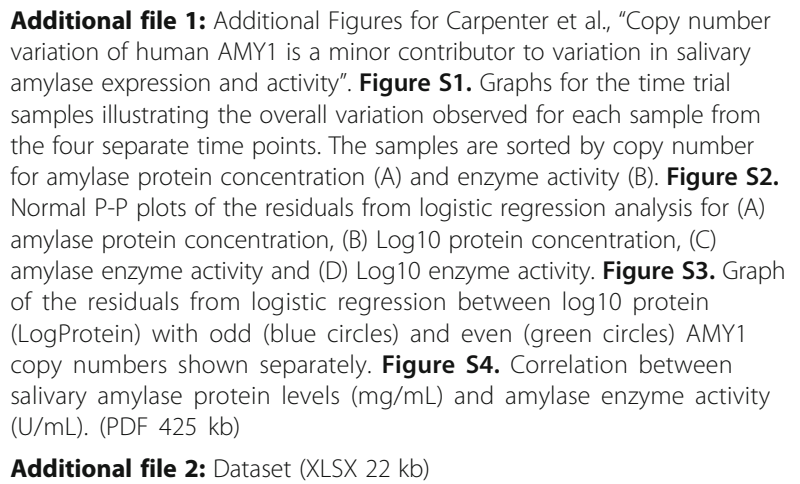

Additional file 2: Dataset (XLSX $22 \mathrm{~kb})$

\section{Abbreviations}

BSA: Bovine serum albumin; CN: Copy number; CNV: Copy number variation/ variant; ELISA: Enzyme-linked immunosorbent assay; HiDi: Highly deionised (formamide)

\section{Acknowledgements}

The authors would like to thank Dr David Sirl (University of Nottingham) for statistical guidance.

\section{Funding}

This work was supported by the Biotechnology and Biological Sciences Research Council [grant BB/1006370/1] (awarded to JALA). The funding body had no role in the design of the study, collection, analysis, interpretation of data or in writing the manuscript.

Availability of data and materials

All relevant data are available in the Additional file 2 dataset. 


\section{Authors' contributions}

DC participated in the study design, coordinated the study, performed copy number typing, optimised the ELISA assay, performed statistical analysis and wrote the manuscript. LM recruited volunteers, performed copy number typing, optimised and performed ELISA assays, optimised and performed enzyme activity assays, performed Bradford assay and generated the DNA from the samples. JALA participated in the study design and wrote the manuscript. All authors read and approved the final manuscript.

\section{Competing interests}

The authors declare that they have no competing interests.

\section{Consent for publication}

Not applicable.

\section{Ethics approval and consent to participate}

Blood and saliva samples were collected with full written, informed consent from healthy volunteers according to the terms of local ethical approval (University of Nottingham Medical School Ethics Committee approval reference number BT10/02/2010). Data from these samples was then analysed anonymously.

Received: 14 October 2016 Accepted: 2 February 2017

Published online: 20 February 2017

\section{References}

1. Noble RE. Salivary alpha-amylase and lysozyme levels: a non-invasive technique for measuring parotid vs submandibular/sublingual gland activity. J Oral Science. 2000;42:83-6.

2. Granger DA, Kivlighan KT, El-Sheikh M, Gordis EB, Stroud LR. Salivary a-amylase in biobehavioral research. Ann N Y Acad Sci. 2007;1098:122-44.

3. Nater UM, Hoppmann CA, Scott SB. Diurnal profiles of salivary cortisol and alpha-amylase change across the adult lifespan: evidence from repeated daily life assessments. Psychoneuroendocrinology. 2013;38:3167-71.

4. Lawrence HP. Salivary markers of systemic disease: noninvasive diagnosis of disease and monitoring of general health. J Canadian Dental Association. 2002:68:170-4

5. Bank RA, Hettema EH, Muijs MA, Pals G, Arwert F, Boomsma DI, Pronk JC. Variation in gene copy number and polymorphism of the human salivary amylase isoenzyme system in Caucasians. Hum Genet. 1992;89:213-22.

6. Mandel AL, Peyrot des Gachons C, Plank KL, Alarcon S, Breslin PAS. Individual differences in AMY1 gene copy number, salivary a-amylase levels, and the perception of oral starch. PLoS One. 2010;5:e13352.

7. Perry GH, Dominy NJ, Claw KG, Lee AS, Fiegler H, Redon R, et al. Diet and the evolution of human amylase gene copy number variation. Nat Genet. 2007;39:1256-60

8. Pronk JC, Frants RR, Jansen W, Eriksson AW, Tonino GJM. Evidence for duplication of the human salivary amylase gene. Hum Genet. 1982;60:32-5.

9. Sudmant PH, Kitzman JO, Antonacci F, Alkan C, Malig M, Tsalenko A, et al. Diversity of human copy number variation and multicopy genes. Science. 2010;330:641-6.

10. Carpenter D, Dhar S, Mitchell L, Fu B, Tyson J, Shwan N, et al. Obesity, starch digestion and amylase: association between copy number variants at human salivary (AMY1) and pancreatic (AMY2) amylase genes. Hum Mol Genet. 2015;24:3472-80.

11. Falchi M, El-Sayed Moustafa JS, Takousis P, Pesce F, Bonnefond A Andersson-Assarsson JC, et al. Low copy number of the salivary amylase gene predisposes to obesity. Nat Genet. 2014:46:492-7.

12. Usher CL, Handsaker RE, Esko T, Tuke MA, Weedon MN, Hastie AR, et al. Structural forms of the human amylase locus and their relationships to SNPs, haplotypes and obesity. Nat Genet. 2015;47:921-5.

13. Groot PC, Bleeker MJ, Pronk JC, Arwert F, Mager WH, Planta RJ, et al. The human a-amylase multigene family consists of haplotypes with variable numbers of genes. Genomics. 1989;5:29-42.

14. Groot PC, Mager WH, Frants RR. Interpretation of polymorphic DNA patterns in the human a-amylase multigene family. Genomics. 1991;10:779-85.

15. Groot PC, Mager WH, Henriquez NV, Pronk JC, Arwert F, Planta RJ, et al. Evolution of the human alpha-amylase multigene family through unequal, homologous, and interchromosomal and intrachromosomal crossovers. Genomics. 1990;8:97-105.
16. Yang Z-M, Lin J, Chen L-H, Zhang M, Chen W-W, Yang X-R. The roles of AMY1 copies and protein expression in human salivary a-amylase activity. Physiol Behav. 2015;138:173-8.

17. Iontcheva I, Oppenheim FG, Troxler RF. Human salivary mucin MG1 selectively forms heterotypic complexes with amylase, proline-rich proteins, statherin, and histatins. J Dent Res. 1997:76:734-43.

\section{Submit your next manuscript to BioMed Central and we will help you at every step:}

- We accept pre-submission inquiries

- Our selector tool helps you to find the most relevant journal

- We provide round the clock customer support

- Convenient online submission

- Thorough peer review

- Inclusion in PubMed and all major indexing services

- Maximum visibility for your research

Submit your manuscript at www.biomedcentral.com/submit
Biomed Central 